\title{
A Casa do Morro: um lugar de memória em Cruzeiro do Sul/RS
}

\author{
Márcia Solange Volkmer*
}

marcia.volkmer@univates.br

Júlia Leite Gregory**

jlgregory@universo.univates.br

\begin{abstract}
Resumo
A Casa do Morro está situada no município de Cruzeiro do Sul/RS e pertenceu à família Azambuja, que fez parte da elite do Vale do Taquari durante o século XIX. A Casa chama a atenção por sua arquitetura imponente e pela sua localização: no alto do morro da antiga Fazenda São Gabriel. O monumento histórico foi eleito símbolo do município em 1969, alguns anos após a emancipação e hoje ocupa lugar de destaque no brasão municipal. Este artigo pretende analisar as escolhas políticas e a vinculação da sociedade local à Casa do Morro, reconhecendo-a como um lugar de memória. A proposta vincula-se à discussão das potencialidades do Ensino de História no estudo dos temas vinculados à memória e patrimônio locais, que na cidade de Cruzeiro do Sul resultaram na criação do grupo Amigos da Casa do Morro para lutar a favor da preservação do monumento.
\end{abstract}

\section{Palavras-chave}

Amigos da Casa do Morro; Lugar de memória; Cruzeiro do Sul

\section{"Casa do Morro": a memory location in Cruzeiro do Sul/RS}

\begin{abstract}
The "Casa do Morro" ("House on the Hill") is located in the town of Cruzeiro do Sul/RS and it belonged to Azambuja family, which was part of the elite of the Taquari's Valley during the 19th century. The House draws attention due to it's imposing architecture and it's location: at the top of the hill of the former São Gabriel Farm. The historical monument was elected as the town's symbol in 1969, a few years after it's emancipation, and nowadays it occupies a distinguished place in the municipal coat of arms. This paper aims at analising the political choices and the linking of the city's society to the "Casa do Morro", recognizing it as a memory location. The proposition binds to the discussion of the potentialities for the teaching of History in the study of the themes linked to local memory and heritage, which resulted in the creation of the group "Amigos da Casa do Morro" ("Friends of the House on the Hill") to fight for the monument's preservation.
\end{abstract}

\section{Keywords}

Amigos da Casa do Morro; Memory location; Cruzeiro do Sul 


\section{Introdução}

Cruzeiro do Sul está situado no Vale do Taquari, localizado na porção centro-leste do Rio Grande do Sul. Dentro do Vale do Taquari, o município se encontra na microrregião centro-oeste e faz fronteira com os municípios de Bom Retiro do Sul, Estrela, Lajeado, Santa Clara do Sul, Venâncio Aires e Mato Leitão. O Vale do Taquari, atualmente com 36 municípios, possui grande diversidade cultural, reflexo da habitação de diferentes grupos étnicos no território, tais como indígenas, africanos e imigrantes europeus. Dentre os últimos são identificados açorianos, alemães, italianos e seus descendentes. A cidade de Cruzeiro do Sul também é caracterizada por essa diversidade cultural. No entanto, no campo patrimonial, grande parte desses grupos sociais estão invisibilizados, ganhando destaque uma memória vinculada aos imigrantes europeus. $\mathrm{Na}$ construção dos sentidos e representações associados ao patrimônio local, acontece o processo de exclusão de vários setores da sociedade.

Se tomamos o patrimônio como uma elaboração de significados, logo ele pode ser interpretado (POULOT, 2009). Conhecendo o seu processo de afirmação, abrem-se possibilidades para a inserção de novos agentes sociais no contexto vivido. "A consequência disso é reconhecer que o patrimônio cultural não se define como dado, mas como construção social e histórica e que se oferece à interpretação histórica" (KNAUSS, 2014, p. 16). Nesse sentido, o Ensino de História, ao possibilitar o estudo dos conceitos de memória, identidade e patrimônio cultural pode oportunizar a produção de novos sentidos patrimoniais, permitindo uma abordagem dos processos culturais.

Ao reconhecermos que as políticas de memória e preservação do patrimônio cultural acabam produzindo uma imagem para o passado, pretende-se alterar a percepção de que determinados grupos sociais não tiveram participação importante na constituição identitária da cidade. "Dentro desse contexto, qualquer patrimônio é entendido como uma escolha política e não como um dado natural, objetivo e incontestável" (CARVALHO; FUNARI, 2010, p. 10). Ao mesmo tempo, essa abordagem permite a compreensão do monumento Casa do Morro em seus aspectos sociais e culturais, para além da vinculação imediata de valor histórico. De acordo com Sandra Pelegrini (2006, p. 503), “quando falamos em bens culturais, não estamos lidando apenas com objetos, saberes ou celebrações, mas também com as formas do homem se conectar ao lugar onde vive no tempo presente". No município de Cruzeiro do Sul, um trabalho desenvolvido na escola de educação básica será a origem dos Amigos da Casa do Morro, um grupo de indivíduos comprometidos com a preservação da memória da cidade.

\section{Uma casa de pedra e cal}

Durante o final do período colonial brasileiro e no transcorrer do período imperial, o governo português concedia sesmarias a quem ocupasse territórios ameaçados de invasão espanhola, no caso da região sul do Brasil. No Vale do Taquari não foi diferente, sendo que várias famílias passaram a ocupar o território que hoje pertence à Cruzeiro do Sul. Em sua grande maioria, são famílias de descendência açoriana e alemã. No entanto, uma família se destacou na história do município, a família Azambuja, que é a fundadora do núcleo urbano de Cruzeiro do Sul (SCHIERHOLT, 2010).

João Xavier de Azambuja e Laura Centeno de Azambuja adquiriram a Fazenda São Gabriel no ano de 1835, mesmo ano em que iniciou a Revolução Farroupilha. A propriedade continha mil e quinhentas braças de frente e seis mil de fundo, confrontando pelo Leste 
com o rio Taquari, pelo Oeste com a Serra Geral, pelo Sul com o Arroio Sampaio e terras de José da Lima Silva e seus irmãos, pelo Norte com terras de Valentim Soares de Saibro (SCHIERHOLT, 2010). No período da compra, a família era residente em Porto Alegre e, logo após, dirigiu-se para a nova propriedade para construir um grande sobrado na localidade de Santarém. $\mathrm{O}$ casal teve onze filhos, os quais foram Primórdio Centeno de Azambuja, Rafael Fortunato Xavier de Azambuja, Bento Manuel de Azambuja, Bento Gonçalves Xavier de Azambuja, Francisca Centeno de Azambuja, João Xavier de Azambuja Júnior, Marcolino Centeno de Azambuja, Josefina Centeno de Azambuja, Maria José de Azambuja, Cândida Centeno de Azambuja e Maria Tomázia Centeno de Azambuja (CHRISTILLINO, 2010).

Os Azambujas pertenciam à elite sul-riograndense e se utilizaram da política dos casamentos, da carreira militar e do comércio de terras para manter seu status social. Com a morte do marido, Laura vendeu uma parte do latifúndio para José Ferreira Guimarães e transferiu-se para o atual centro urbano do município. A família Azambuja possuía escravos que trabalhavam na propriedade servindo à família no trato com os animais, no trabalho na lavoura e no engenho de serrar madeira. O primogênito do casal, Primórdio Centeno de Azambuja, acabou herdando as posses e deu continuidade às atividades, no entanto, também passou a comercializar a terra, em lotes coloniais. Primórdio, quando voltou da Guerra do Paraguai, iniciou a construção de sua casa, em 1872, ao lado da casa de sua mãe, a qual estava situada onde hoje se encontra o prédio da prefeitura de Cruzeiro do Sul. Durante a construção da casa, uma enchente atingiu a obra, e Primórdio resolveu erguer sua moradia no alto do morro da Fazenda São Gabriel, que compreende uma grande área de terra repleta de árvores nativas e rochas, e que tem o início de sua elevação próximo à margem do rio Taquari, encontrando-se no atual centro urbano de Cruzeiro do Sul. A casa foi concluída por volta do ano de 1878 .

Primórdio mandou construir uma casa de pedra e cal, coberta com telhas de barro (Inventário $n^{\circ} 371$, APERS, 1902), com arquitetura típica do período imperial, que ficou conhecida, primeiramente, como a Casa Branca dos Arcos do Morro, sendo que, atualmente, é denominada de Casa do Morro. O prédio contém $305,30 \mathrm{~m}^{2}$ de área construída e possui uma arquitetura mista, tendo em sua fachada sete arcos (SCHIERHOLT, 2010). Possivelmente as características da arquitetura neoclássica brasileira tenham exercido influência na construção do prédio.

Analisando as fotografias da Casa do Morro, é possível perceber diversas mudanças estruturais ao longo do tempo. Acima dos arcos existiam estátuas e pinhas, no entanto, atualmente as estátuas não existem mais, e no lugar delas foram construídas pinhas. Além disso, há discursos de que, em uma forte tempestade, tenha caído um raio sobre a fachada da casa, destruindo uma parte dos arcos, que foram reconstruídos. Desde a sua construção, que levou em torno de cinco anos, entre 1873 e 1878, a casa já sofreu diversas alterações (SCHIERHOLT, 2010). Na década de 1940, as estátuas já não estavam mais presentes na fachada, aproximando -se da aparência que a casa tem ainda hoje.

E lá no topo do morro, não muito longe da citada figueira, está a "casa mal assombrada", hoje pertencente à familia Lopes. Muitas histórias de lobisomem e fantasma correm pela boca do povo em torno dela. Essa casa dos velhos amigos de Gonçalves é de estilo colonial bem típico, dos primeiros tempos do Primeiro Império, ostentando ainda os restos de estilo arquitetônico usual naquela época. Diante da fachada principal, repartida por numerosas janelas de arco, levantase, a pouco mais de metro, uma fileira de colunas, cujos arcos ligam em cima com o telhado, sendo o vão embaixo, à guisa 
de varanda ou passeio, coberto com lajes. Obteve-se destarte uma fachada dupla. Faz anos, havia uma fileira de estátuas no topo da fachada, correspondendo ao número de colunas. Hoje há apenas uns restos. Diz o povo que o raio abateu as estátuas (HARNISCH, 1941, p. 380).

Primórdio morou na casa até 1898 , quando veio a falecer no dia 17 de maio, de causa natural, sem assistência médica, com 76 anos de idade. Primórdio não deixou uma grande fortuna, a qual foi dividida entre seus netos e sua filha Maria Altina. Além disso, tinha diversas dívidas, que ultrapassavam a metade do valor do monte mor. A casa foi vendida em hasta pública em 1901, para Leocádia Villanova de Azambuja, esposa de Rafael Fortunato de Azambuja, pelo valor de seiscentos mil réis (Inventário ${ }^{\circ} 371$, APERS, 1902).

Até 1914, o prédio permaneceu sob a tutela de Leocádia, sendo que a última herdeira da casa foi Nathercia Raphaela de Azambuja Terra, filha de Rafael e Leocádia. Sárah de Azambuja Neves, neta de Nathercia, relata alguns objetos que existiam na Casa do Morro, como um imenso armário-cristaleira, com espelho de cristal e pedra mármore, castiçais de metal dourado e opalina azul, sopeiras de porcelana inglesa e talheres de prata. Sárah conservou algumas peças do mobiliário, utensílios, livros, roupas e objetos da família Azambuja (Centro Cultural 25 de Julho "Vale do Taquari”, 1985).

Posteriormente, a casa foi ocupada por outras famílias, dentre elas a família Lopes, Souza e Guterres (ZERO HORA, 1999), sendo que, no dia 7 de agosto de 1962, por meio de um decreto, a Prefeitura Municipal de Lajeado declara de utilidade pública, para fins de desapropriação, a propriedade da Casa do Morro, que tinha como proprietário Armando Lopes (LAJEADO, 1962). Esse decreto é amparado pelo decreto-lei $\mathrm{n}^{\circ}$ 3365, de 1941, que trata das desapropriações por utilidade pública, e funciona como uma ferramenta infra- constitucional de regulamentação para a realização das desapropriações. Um dos objetivos do decreto é

a preservação e conservação dos monumentos históricos e artísticos, isolados ou integrados em conjuntos urbanos ou rurais, bem como as medidas necessárias a manter-lhes e realçar-lhes os aspectos mais valiosos ou característicos e, ainda, a proteção de paisagens e locais particularmente dotados pela natureza (BRASIL, 1941).

Mesmo tendo o primeiro amparo legal para sua preservação e conservação como monumento histórico, a Casa do Morro não recebeu nenhum tratamento especial neste primeiro momento. A partir daí, foi ocupada por inquilinos e, mais tarde, serviu de abrigo a um restaurante, a um museu municipal e à biblioteca municipal. Algumas lendas sobre a Casa do Morro ainda permanecem vivas no imaginário da comunidade cruzeirense, como a suposta presença de ouro no porão e de fantasmas. Ao longo dos anos, a Casa sofreu intensa degradação causada pelo tempo e pela ação humana, mesmo passando por alguns processos de reforma. A Casa está fechada desde o ano de 2003, mas é de fácil acesso a vândalos. O monumento histórico se encontra no centro do Brasão de Armas do município e está tombado em nível municipal, desde 2006.

Somente após dez anos do tombamento é que a Casa passou a receber intervenções em sua estrutura, que buscam salvaguardar o prédio, o qual estava prestes a ruir. Recentemente, um grupo de alunas do Ensino Médio elaborou um trabalho de pesquisa em que ressaltaram a importância do patrimônio histórico para o município e solicitaram a restauração do prédio e organização de um espaço cultural nele. A solicitação foi levada ao Poder Legislativo municipal e, a partir daí, foi criado o grupo Amigos da Casa do Morro, em março de 2015. O objetivo do grupo de voluntários é angariar fundos para a restauração do monumento e a disposição de um espaço cultural que ofereça variadas atividades, como 
teatro, música, artesanato e dança. Atualmente a Casa está passando por um processo de reestruturação, que começou em decorrência do movimento dos Amigos da Casa do Morro, mas ainda não está definido para qual propósito a Casa será utilizada.

\section{Patrimônio, identidade e memória}

Os patrimônios nacionais sempre foram tutelados pelo Estado, pensados por intelectuais, logo, esses patrimônios ditos oficiais dizem respeito às classes dominantes, que buscam criar símbolos nacionais que identifiquem a população com a nação como uma forma de educação. Porém, dessa forma, apenas um setor da população se vê reconhecido, pois consegue identificar-se com determinados objetos, os quais são remetidos à memória do grupo. Os outros grupos da população acabam sendo excluídos do campo patrimonial, sendo forçados a incorporarem outros objetos às suas concepções de identidade. Embora, ao longo dos anos, esses grupos passem a ser representados, suas manifestações culturais ainda têm um longo caminho a percorrer para que sejam realmente reconhecidas (FONSECA, 2005).

No Brasil, as políticas públicas de preservação do patrimônio nacional também foram pensadas por intelectuais e, no ano de 1936, criou-se o Serviço do Patrimônio Histórico e Artístico Nacional (SPHAN), que tinha como objetivo proteger os bens culturais do país. Seus membros defendiam que o patrimônio cultural da nação não era representado apenas por monumentos e obras de arte. Entretanto, a única prática preservacionista aplicada era o tombamento, o que acabava excluindo do campo patrimonial uma série de outros bens. $\mathrm{O}$ Sphan foi criado pelo ministro da Educação e Saúde Pública da época, Gustavo Capanema (FONSECA, 2006).

Durante o período populista, o patrimônio arque- ológico passou a ser reconhecido. No período do regime militar, com o Ato Institucional n. 5, alguns impasses foram criados para a preservação do patrimônio cultural. A partir da década de 1970, o governo federal passou a incentivar a criação de vários programas em prol da cultura e da preservação do patrimônio. Entre eles estão o Programa de Reconstrução das Cidades Históricas, Programa de Ação Cultural (PAC), Política Nacional de Cultura, Centro Nacional de Referência Cultural (CNRC), Fundação Nacional Pró-Memória, entre outros. O CNRC (1975) propunha distinguir-se das outras instituições oficiais, propondo uma nova forma de atuação na área da cultura. O Centro buscava definir um sistema referencial básico para a descrição e análise da dinâmica cultural brasileira (FUNARI; PELEGRINI, 2006).

A partir da década de 1980, com a queda do regime militar, novas discussões sobre as práticas preservacionistas ocorreram. Outras manifestações culturais também passaram a ser preservadas, como as indígenas e afro-brasileiras, ou de qualquer outro grupo social. Vários projetos de restauração foram implementados no país, como é o caso do Pelourinho, na cidade de Salvador, Bahia (FONSECA, 2005). De acordo com Pedro Funari e Sandra Pelegrini,

apesar do valor positivo desses projetos,
pautados pela transformação do patri-
mônio em áreas de interesse turistico, a
implantação de programas dessa nature-
za deve escapar à tentação de reduzir o
patrimônio a "cenários" da indústria
cultural e à lógica do entretenimento,
dissociando toda a fruição dos bens cul-
turais da memória social e histórica
(FUNARI; PELEGRINI, 2006, p. 53-54).

A partir da década de 1970, já com o Instituto do Patrimônio Histórico e Artístico Nacional (IPHAN), antigo SPHAN, novas práticas preservacionistas começaram a ser pensadas. As manifestações culturais de outros grupos sociais passaram a fazer parte do patri- 
mônio cultural brasileiro, e não somente os monumentos da história oficial, a qual as elites pertenciam. No entanto, somente com o Decreto n.3.551/2000, bens culturais de natureza imaterial passaram a ser registrados pelo órgão (FUNARI; PELEGRINI, 2006). O IPHAN tem a incumbência de identificar, catalogar, restaurar, conservar, preservar, fiscalizar e difundir os bens culturais em todo o território brasileiro.

Foi nas décadas de 1970 e 1980 que os intelectuais responsáveis pelas políticas públicas de preservação do patrimônio passaram a defender a ideia de que o processo de definição dos patrimônios deveria ser realizado em conjunto com a sociedade, de forma democrática (FONSECA, 2005). Foi nesse período que a noção de referência cultural foi introduzida no vocabulário das políticas de patrimônio, suscitando "indagações sobre quem tem legitimidade para selecionar o que deve ser preservado, a partir de que valores, em nome de que interesses e de que grupos" (FONSECA, 2001, p. 111112). A partir dessas indagações, pode-se concluir que a preservação é uma demonstração de poder, pois, grosso modo, são os poderosos que conseguem preservar a representação da sua identidade, em detrimento de outras representações culturais. No entanto, consideravase que todas as manifestações culturais deveriam integrar o patrimônio cultural brasileiro, representações de todos os grupos que compõem a sociedade brasileira.

A expressão referência cultural, baseada em uma concepção antropológica de cultura, enfatiza a diversidade da produção material, dos sentidos e valores atribuídos pelos diferentes sujeitos a bens e práticas sociais. As manifestações culturais só podem ser definidas como referências culturais "quando são consideradas e valorizadas enquanto marcas distintivas por sujeitos definidos" (FONSECA, 2001, p. 113), quando representam a identidade dos sujeitos envolvidos.
Referências culturais não se constituem, portanto, em objetos considerados em si mesmos, intrinsecamente valiosos, nem apreender referências significa apenas armazenar bens ou informações. Ao identificarem determinados elementos como particularmente significativos, os grupos sociais operam uma ressemantização desses elementos, relacionando-os a uma representação coletiva a que cada membro do grupo de algum modo se identifica. $O$ ato de apreender referências culturais pressupõe não apenas a captação de determinadas representações simbólicas, como também a elaboração de relações entre elas e a construção de sistemas que "falem" daquele contexto cultural, no sentido de representá-lo. Nessa perspectiva, os sujeitos dos diferentes contextos culturais têm um papel não apenas de informantes como também de intérpretes de seu patrimônio cultural (FONSECA, 2001, p. 113-114).

Nessa perspectiva, com o Decreto $n^{\circ}$ 3.551/2000, foi criado o Registro de Bens Culturais de Natureza Imaterial, que oficializou outras formas de reconhecimento do patrimônio histórico nacional. A partir de então, artesanatos, maneiras de pescar, caçar, plantar, cultivar e colher, de utilizar plantas como alimentos e remédios, de construir moradias, a culinária, as danças e músicas, os modos de vestir e falar, os rituais e festas religiosas e populares, as relações sociais e familiares, bem como os objetos históricos e artísticos, monumentos representativos da memória e centros históricos já consagrados e protegidos pelas instituições e agentes governamentais, passaram a constituir o patrimônio cultural nacional (FONSECA, 2005).

Como exemplos de patrimônios imateriais brasileiros temos a capoeira, o frevo, o maracatu, o samba de roda, o fandango, a chula, o forró, o carnaval e o chimarrão. Além disso, o Brasil também está repleto de patrimônios ambientais como o Corcovado, as cataratas de Foz do Iguaçu e o Pantanal. Os monumentos naturais, os sítios e as paisagens que importe conservar e proteger pela feição notável dada pela natureza ou pela ação do homem são passíveis de tombamento, portanto, 
podem ser considerados patrimônios, tanto paisagens autóctones quanto não autóctones, como uma mata virgem ou um jardim botânico. De acordo com Sandra Pelegrini "essa exuberância natural e riqueza cultural nos preenchem de um sentimento vigoroso que nos vincula às nossas tradições e nutre o sentido de pertença aos nossos lugares de origem. Todos esses elementos integram a nossa 'brasilidade', nossa identidade comum" (PELEGRINI, 2009, p. 14).

Porém, apesar de existir a valorização das tradições orais, saberes e ofícios de todas as culturas brasileiras, principalmente daquelas invisibilizadas pelas culturas dominantes, percebe-se que o patrimônio material ainda é mais valorizado que o patrimônio imaterial das cidades. Os conjuntos arquitetônicos são tratados como símbolos da memória oficial das nações, sendo utilizados desta maneira pelos representantes políticos das sociedades, que têm a pretensão de transformá-los em símbolos do poder estatal, das suas instituições e dos setores dirigentes da população. Isto ocorre em detrimento dos bens culturais produzidos por outros setores da população, embora estes venham reivindicando a preservação e o reconhecimento das suas manifestações culturais, tanto materiais quanto imateriais, amparados pela legislação vigente (PELEGRINI, 2009).

A estratégia mais comum de preservação dos monumentos históricos empregada pelo poder público, aliada à iniciativa privada, é a reutilização desses espaços de maneira autossustentável e direcionada ao turismo. No entanto, essas estratégias acabam limitando-se à restauração das fachadas, à limpeza dos monumentos e à exclusão da população pobre dessas áreas, as quais são transformadas em núcleos com padrões burgueses. Poucos são os casos em que houve um processo de restauração patrimonial concomitante com um projeto de política habitacional para amparar as camadas pobres da sociedade que viviam em locais a serem restaurados.
Poucos são os casos também em que essa população foi beneficiada com a atração turística que essas restaurações proporcionaram (PELEGRINI, 2009).

Apesar disso, o campo de estudo da Educação Patrimonial vem buscando levar as pessoas a interagirem, conhecerem e a se identificarem com o seu patrimônio cultural, para que ocorra a preservação consciente dos bens culturais, e o reconhecimento da sua própria história cultural, tornando-as sujeitos históricos, e não apenas espectadores. Esse método fortalece os sentimentos de identidade e cidadania, e pode ser aplicado sobre qualquer manifestação da cultura, podendo ser um objeto, um monumento, um sítio arqueológico, uma paisagem natural, uma manifestação popular, ou qualquer outra expressão resultante da relação entre os indivíduos e seu meio ambiente (HORTA, 1999).

Horta define a Educação Patrimonial como "um processo permanente e sistemático de trabalho educacional centrado no Patrimônio Cultural como fonte primária de conhecimento e enriquecimento individual e coletivo" (HORTA, 1999, p. 6). Portanto, a Educação Patrimonial não se restringe apenas aos ambientes escolares, podendo ser realizada em qualquer espaço que propicie experiências ou contatos com manifestações da cultura por parte da sociedade.

Neste trabalho, consideram-se justamente as experiências de contato cultural, e o conceito de patrimônio será tratado como resultado de uma escolha política. Por conseguinte, o conceito de identidade será analisado como uma construção social, não estática, que sofre alterações ao longo do tempo. A Casa do Morro de Cruzeiro do Sul será interpretada como um lugar de memória que desperta em muitas pessoas o sentimento de representatividade de sua identidade.

A Casa do Morro passou a ser o símbolo oficial de Cruzeiro do Sul em 1969, a partir das Leis $\mathrm{n}^{\circ}$ 
109/1969 (Brasão de Armas) e no 110/1969 (Bandeira) (LOCATELLI et al, 2012, p. 43-44). Os representantes da população fizeram uma escolha para elaborar os símbolos do município, e essa opção deu destaque para representações elitistas, como a Casa do Morro. Essa escolha política, realizada pelo pequeno grupo social, elegeu o patrimônio histórico com o intuito de que ele contribuísse para a construção da identidade do novo município. Percebemos que a opção feita reforça a ideia tradicional e conservadora sobre patrimônio, aquela que entende patrimônio apenas como obras materiais, em especial monumentos herdados de gerações anteriores.

Os símbolos não brotam do instinto nem são fotografias da realidade. São antes peças criadas para promover, divulgar, exaltar certos conteúdos importantes na coletividade que os adota. Na medida em que destacam atividades e comportamentos, eles, ao mesmo tempo, revelam caracteristicas de quem os elegeu. Assim, mesmo quando os hinos ou brasões são criações encomendadas a autores estranhos à comunidade, constituem testemunho importante. Se não foram criados por munícipes, os símbolos são por eles aceitos e reconhecidos como representativos de seu pensamento. Lembremos que os símbolos resultam da convergência de ideias, de construções convencionais; tornam-se legitimos porque têm a cultura vigente na base. Nesta medida, os símbolos são capazes de tornar sensiveis os valores compartilhados ou, ao menos, podem ser tomados como peças relevantes, quando se procura identificar os valores a eles subjacentes (HUPPES in NICOLINI, 2013, p. 78).

O principal símbolo da cidade de Cruzeiro do Sul destaca a aristocracia advinda da cultura açoriana do Vale do Taquari, deixando à margem outros elementos culturais provenientes da presença de negros escravizados e libertos, e povos indígenas na região. Esta última é evidenciada pela grande produção de aipim do município, cultivo tradicionalmente associado a grupos indígenas, e é destacada pela feira denominada Expo Cruzeiro que ocorre concomitantemente com a Festa do Aipim a cada dois anos e já teve seis edições. A presen- ça indígena no município também já foi estudada pelo pesquisador Pedro Augusto Mentz Ribeiro, que realizou coleta de cerâmica guarani na margem esquerda do Arroio Castelhano (SCHIERHOLT, 2010), e novas pesquisas foram realizadas pelos grupos de pesquisa e arqueologia da UNISC e UNIVATES.

Christillino (2004) aponta também para a presença de um grupo heterogêneo em relação à sua formação chamado de lavradores nacionais, responsável por uma grande parcela da produção agrícola do país durante o século XIX. Os lavradores nacionais estiveram presentes no Vale do Taquari atraídos pelas terras férteis, ricas em recursos naturais, atuando no trabalho com as plantações de ervais, e também como mão-deobra livre da elite fundiária. Muitos tiveram suas terras expropriadas pelos processos de grilagens e especulações fundiárias ocorridas intensamente após a Lei de Terras de 1850.

A família Xavier de Azambuja, considerada a precursora do município de Cruzeiro do Sul, sempre é exaltada e posta em destaque quando se fala na história e origem do município. "O Município de Cruzeiro do Sul, que incorporava originariamente uma região que era rica em ervais no século XIX, nos quais havia uma grande quantidade de trabalhadores neles alojados, desconsiderou a contribuição destes, se restringindo apenas à Família Azambuja" (CHRISTILLINO, 2004, p. 298).

A respeito do conceito de memória, Joël Candau (2014) define três diferentes manifestações da memória individual. A primeira, a protomemória, é imperceptível e ocorre sem a tomada de consciência. É o primeiro estágio da memória, aquele que desenvolvemos ainda na barriga da mãe, e tem uma estreita ligação com o nosso corpo. Ela é responsável pelo armazenamento de informações que dizem respeito principalmente a ações, as quais são efetuadas sem que tenhamos consciência 
do que estamos fazendo. O segundo estágio, a memória propriamente dita, é responsável pela capacidade de lembrar, reconhecer e esquecer. Já a metamemória não depende da faculdade de memória, como as duas anteriores, ela é uma representação relativa a essa faculdade, uma representação de como nós interpretamos e descrevemos nossa memória. É nesse estágio que ocorre a construção da identidade, em que a memória se manifesta de maneira ostensiva. Já na memória coletiva, só é possível uma forma de metamemória, que atua como representação, e não como faculdade, "um enunciado que membros de um grupo vão produzir a respeito de uma memória supostamente comum a todos os membros desse grupo" (CANDAU, 2014, p. 24).

O conceito de memória é apresentado por Duarte como uma função que garante, em toda sociedade, o domínio, a preservação, a transmissão e a continuidade do significado de todas as coisas. E que ao longo do tempo vem sendo sistematizada por várias ferramentas que procuram eternizar a memória, como a escrita e, atualmente, os instrumentos da indústria da informação. Essas ferramentas podem apresentar um perigo à memória coletiva, pois aparecem como um recurso suplementar à mnemotecnia, a arte de desenvolver a memória por meio de exercícios apropriados, ou seja, esses meios podem representar a substituição da elaboração íntima, vivenciada, experienciada da memória (DUARTE, 2009).O pensamento de Nora vai ao encontro do de Duarte, quando diz que a memória é um processo vivo e dinâmico vivenciado por todos os grupos, étnicos e/ou sociais, constituindo-se como um fenômeno sempre atual. Diferente da história, que possui caráter universal, comum a todos, e que é uma representação do passado. A respeito dessa diferenciação, e da relação das mesmas, o autor destaca:

Aceitemos isso, mas com a consciência clara da diferença entre memória verda- deira, hoje abrigada no gesto e no hábito, nos oficios onde se transmitem os saberes do silêncio, nos saberes do corpo, as memórias de impregnação e os saberes reflexos e a memória transformada por sua passagem em história, que é quase o contrário: voluntária e deliberada, vivida como um dever e não mais espontânea; psicológica, individual e subjetiva e não mais social coletiva, globalizante. Da primeira, imediata, à segunda, indireta, o que aconteceu? Pode-se apreender o que aconteceu, no ponto de chegada da metamorfose contemporânea (NORA, 1993, p. 14).

Com o esquecimento da memória tradicional, obrigamo-nos a criar lugares de memória como arquivos, museus e bibliotecas, que transformaram a memória em história e acabaram tornando-se gigantescos armazenadores de informações que não somos capazes de lembrar. A memória contida nos arquivos é interiorizada como uma obrigação individual, e não mais como uma prática social.

Os lugares de memória podem ser materiais ou imateriais, desde que sejam simbólicos e funcionais e, principalmente, que incitem uma "vontade de memória”. "A passagem da memória para a história obrigou cada grupo a redefinir sua identidade pela revitalização de sua própria história" (NORA, 1993, p. 17). Sendo assim, os lugares de memória representam o encontro da memória e da história, fazendo com que diversos grupos busquem neles sua identidade e origem. Com o desaparecimento da memória espontânea, os grupos reconstituem sua memória a partir dos lugares de memória para que possam definir sua identidade, criando operações não naturais como celebrações e aniversários para rememorar o passado.Essa necessidade dos grupos de buscarem sua origem é devida, de acordo com Nora, à fragmentação da sociedade contemporânea, que acabou com a história-memória e multiplicou as memórias particulares. Portanto, "os lugares de memória são espaços criados pelo indivíduo contemporâneo diante da crise dos paradigmas modernos, e que com esses espa- 
ços se identificam, se unificam e se reconhecem agentes de seu tempo, isto é, a tão desejada volta dos sujeitos" (NORA in ARÉVALO, 2004, p. 6).

A busca dos grupos por sua origem também é uma busca para encontrar ou reafirmar sua identidade, seja ela individual ou coletiva. Nesse sentido, entendemos o conceito de identidade como resultado de uma construção social, que acontece em uma relação dialética com o outro. Entretanto, ao contrário do que é discutido no ambiente acadêmico, no cotidiano dos indivíduos, suas identidades continuam a ser representadas em aspectos essencialistas. Ou seja, há a tendência de generalizarmos grupos sociais de acordo com sua "essência", ao transformar uma característica singular em geral, como por exemplo, os estereótipos cultural e nacional (CANDAU, 2006).

Entretanto, sabemos que não morremos da mesma forma que nascemos. Ao longo da vida, modificamos nossas concepções e atitudes constantemente, e isso se deve ao nosso convívio em sociedade e às diferentes vinculações sociais estabelecidas, como por exemplo, de sexo, de idade, de nação, de classe social, de grupo cultural. Portanto, "cada indivíduo integra, de forma sintética, a variedade das referências identificatórias que estão ligadas à sua história" (BERLATTO, 2009, p. 148), sendo detentor de uma identidade sincrética. "Essas variações situacionais da identidade impedem de reificá-la, de reduzi-la a uma essência ou substância" (CANDAU, 2014, p. 27).

[...] As identidades não se constroem a partir de um conjunto estável e objetivamente definivel de "traços culturais" vinculações primordiais -, mas são produzidas e se modificam no quadro das relações, reações e interações sociossituacionais - situações, contexto, circunstâncias -, de onde emergem os sentimentos de pertencimento, de "visões de mundo" identitárias ou étnicas. Essa emergência é a consequência de processos dinâmicos de inclusão e exclusão de dife- rentes atores que colocam em ação estratégias de designação e de atribuição de características identitárias reais ou fictícias, recursos simbólicos mobilizados em detrimento de outros provisória ou definitivamente descartados (CANDAU, 2014, p. 27).

Nesse sentido, ao mesmo tempo em que nos identificamos também nos diferenciamos dos grupos culturais com que convivemos. Essa capacidade de alteridade também é uma característica identitária, pois por meio do contato com o diferente, aspectos próprios da identidade se manifestam numa rede complexa de significados, que tanto pela aproximação, quanto pela oposição reforçam os valores culturais dos grupos que compartilham deste contato.

A identidade está intimamente ligada à memória, sendo que as duas adquirem um caráter de interdependência, pois a memória faz com que a identidade sobreviva ou não ao longo do tempo, podendo ser responsável tanto pelo seu reforço (através da lembrança) quanto pelo seu enfraquecimento (através do esquecimento). Entretanto, a memória também depende da identidade, pois os indivíduos e os grupos fazem suas escolhas memoriais (por exemplo, escolhas patrimoniais) de acordo com aquilo que os identifica (sua identidade). Daí a necessidade dos grupos de preservar aquilo que os representa, de preservar sua identidade com o objetivo de a patrimonializar. Essa preocupação com a patrimonialização vai ao encontro do interesse dos grupos em afirmar sua identidade e reconhecer os elementos que a constituem, obtendo, assim, representações identitárias que os diferenciam culturalmente. Representações que podem constituir-se lugares de memória, como afirma Pierre Nora. “Assim, certas ações de patrimonialização estão na origem de memória e identidade. Logo, a patrimonialização desempenha um papel essencial para autentificar uma narrativa coletiva de um passado compartilhado" (CANDAU, 2010, p. 49). 
Sendo assim, os grupos sociais escolhem os seus patrimônios, tanto materiais quanto imateriais, de acordo com sua memória e identidade, respeitando uma demanda do tempo vivido. O patrimônio cultural é uma construção social e histórica que parte da própria sociedade, de forma democrática e participativa (KNAUSS, 2014). No entanto, muitos setores sociais nunca se sentiram representados pelos símbolos nacionais impostos pelo Estado, afinal, esses símbolos sempre representaram as camadas dominantes da sociedade. A constituição de memórias e identidades nacionais a partir da escolha de determinados símbolos afeta intimamente a diversidade cultural de um país, pois deixa desassistidos, invisibilizados e marginalizados vários grupos étnicos e sociais.

O reflexo que essa política de patrimônio empregada pelo Estado causou é o pensamento quase que hegemônico da ideia simplista de patrimônio histórico e cultural, a qual evoca "um conjunto de monumentos antigos que devemos preservar, ou porque constituem obras de arte excepcionais, ou por terem sido palco de eventos marcantes, referidos em documentos e em narrativas dos historiadores" (FONSECA, 2009, p. 59).

A partir da Constituição Federal de 1988, os bens imateriais também passaram a integrar o patrimônio cultural brasileiro, constituído a partir de então pelas formas de expressão, modos de criar, fazer e viver, criações científicas, artísticas e tecnológicas, obras, objetos, documentos, edificações e demais espaços destinados às manifestações artístico-culturais, conjuntos urbanos e sítios de valor histórico, paisagístico, artístico, arqueológico, paleontológico, ecológico e científico. Para auxiliar na preservação desses bens culturais, existem alguns mecanismos criados pelo Estado para desempenhar essa função, como é o caso do tombamento, do registro e de leis de propriedade intelectual e de direito autoral. No entanto, algumas manifestações culturais acabam ficando prejudicadas por não terem um amparo específico de proteção, que se restringe à integridade física dos bens. Essa preocupação com o patrimônio imaterial é bastante atual e, de acordo com Fonseca, ater-se apenas à proteção física é esquecer o que a justifica.

\begin{abstract}
Para que essa função se cumpra, é necessário que a ação de "proteger" seja precedida pelas ações de "identificar" e "documentar" - bases para a seleção do que deve ser protegido -, seguida pelas ações de "promover" e "difundir", que viabilizam a reapropriação simbólica e, em alguns casos, econômica e funcional dos bens preservados (FONSECA, 2009, p. 67).
\end{abstract}

Nesse sentido, é importante que a sociedade participe do processo de construção e de apropriação de seu patrimônio cultural, afinal, o patrimônio representa os grupos sociais. É evidente que só a preservação física não basta para perpetuar a ideia de patrimônio dos bens culturais. É necessária uma ação constante de relação da sociedade com esses patrimônios, uma relação que estabeleça vínculos com a memória e a identidade social, para que a representação destas, o patrimônio, não caia no esquecimento, entendendo que a preservação do patrimônio cultural é uma prática social (ARANTES in FONSECA, 2009).

\section{Ensino de História e Patrimônio: os amigos da Casa do Morro}

Em 2014, uma parcela da comunidade cruzeirense organizou e criou o grupo denominado Amigos da Casa do Morro, com o objetivo de pensar ações possíveis para angariar fundos com o propósito de investir na reforma e posterior revitalização da Casa do Morro. Neste momento, a iniciativa surgiu da própria população, que também enseja ver a Casa do Morro aberta ao público e como um espaço cultural, e não somente como um espaço de sentido pragmático. A partir dos questionários realizados com os integrantes do grupo, 
foi possível entender como e por que o grupo foi criado, de que maneira este se articula para efetuar suas reivindicações e o que a Casa do Morro representa para ele.

O grupo foi criado a partir da iniciativa de algumas alunas do Ensino Médio em propor a revitalização da Casa do Morro por meio de um trabalho de pesquisa realizado na escola. Em outubro de 2014 (ATA n $^{\circ}$ 020/2014), as alunas apresentaram o trabalho na Câmara Municipal de Vereadores de Cruzeiro do Sul, o qual foi bastante elogiado pelos vereadores, e tomado como exemplo de propostas que os próprios vereadores deveriam elaborar. Após a realização do trabalho de pesquisa, as alunas e a professora responsável pela proposta passaram a movimentar a população com o intuito de constituir o grupo denominado Amigos da Casa do Morro, que teria o objetivo de angariar verbas para a reforma e posterior revitalização do prédio.

O primeiro passo foi criar algo que identificasse o grupo, surgindo então a ideia da camiseta com a imagem da Casa do Morro estampada. O grupo apresentou sua proposta ao Prefeito do município, que demonstrou interesse e ofereceu apoio ao movimento, e deu início às suas atividades. Ocorreram vários encontros envolvendo a população e voluntários do Poder Público, bem como a realização de eventos e vendas de camisetas e outros artesanatos elaborados com o tema da Casa do Morro. Além dessas ações para obter fundos para a reforma da Casa do Morro, os vereadores aprovaram por unanimidade o Projeto de Lei $\mathrm{n}^{\mathrm{o}}$ 052-03/2015 (CRUZEIRO DO SUL, 2015) do Poder Executivo que autoriza o município a receber doações materiais e produtos de construção para a reforma da Casa do Morro, sendo que as doações podem ser feitas por pessoas físicas e jurídicas, mediante controle e aceite da Secretaria Municipal de Educação e Cultura. A partir de então, a Casa do Morro passou a receber intervenções em sua infraestrutura com o objetivo de salvaguardar o que ainda restava do prédio, sendo que as obras ainda estão em andamento.

O grupo Amigos da Casa do Morro é bastante heterogêneo em se tratando da faixa etária dos participantes e das suas áreas de atuação, assim como não podemos confirmar ao certo o número exato de cidadãos que fazem parte do grupo, pois esse não é organizado como uma associação. Por meio de questionários foi possível compreender alguns aspectos do grupo e perceber como este entende a Casa do Morro. Como já relatado anteriormente, o principal objetivo do grupo é a recuperação da infraestrutura da Casa do Morro para que ela possa ser aberta ao público novamente e ofereça atividades culturais para a população. Além disso, o grupo também busca sensibilizar a comunidade cruzeirense para a preservação deste importante patrimônio histórico que faz parte da história do município.

A Casa do Morro é importante para essas pessoas por ser o principal símbolo de Cruzeiro do Sul, por fazer parte da história do município, e por ser um importante ponto turístico. Alguns salientam que a história da cidade inicia com a construção da Casa pela família Azambuja, sendo importante a preservação do prédio para que seja possível conhecer o passado e valorizar no presente tudo que for possível e tiver significado, mantendo a história viva. Esse pensamento vai ao encontro do que o grupo entende como patrimônio: algo que conta a história de um povo e que é herdado por gerações anteriores; que deve ser preservado para manter viva a memória e a cultura de um povo. Afirmam que a Casa do Morro representa a identidade de Cruzeiro do Sul.

Entretanto, quando questionados a respeito do envolvimento da população com este monumento, declaram que, além do grupo Amigos da Casa do Morro, 
há uma parcela da sociedade que se preocupa com a Casa, mas que não se mobiliza para mudar a situação em que ela se encontra, talvez por acreditarem que essa responsabilidade seja somente do Poder Público. Porém, também há aqueles que não se identificam com essa obra, fato que pode ser atribuído ao não conhecimento da história do município.

A Casa do Morro é interpretada pelas pessoas que se identificam com ela como um lugar que abriga a história de Cruzeiro do Sul, e temem pelo desaparecimento do prédio, pois, com isso, esta história também fica condenada. A Casa do Morro representa o encontro da memória e da história, levando em consideração que a memória é tudo o que é vivido e história é a representação do passado, portanto, ela é um lugar de memória. Esses lugares são criados devido à fragmentação da sociedade contemporânea, que nos afasta de nossa memória e identidade, levando a uma crise de existência. Tem -se a sensação de que tudo está fadado ao esquecimento, por isso consagramos lugares e celebrações que guardem informações que não somos mais capazes de lembrar.

Se habitássemos ainda nossa memória, não teríamos necessidade de lhe consagrar lugares. Não haveria lugares porque não haveria memória transportada pela história. Cada gesto, até o mais cotidiano, seria vivido como uma repetição religiosa que sempre se fez, numa identificação carnal do ato e do sentido. Desde que haja rastro, distância, mediação, não estamos dentro da verdadeira memória, mas dentro da história (NORA, 1993, p. 8-9).

Os lugares de memória adquirem um grande valor simbólico para aqueles que os consagram. Podem ser museus, arquivos, cemitérios, coleções, festas, aniversários, tratados, monumentos, santuários e associações que suprem, de certo modo, uma carência social que está cada vez mais distante: a memória. "O tempo dos lugares, é esse momento preciso onde desaparece um imenso capital que nós vivíamos na intimidade de uma memória, para só viver sob o olhar de uma história reconstituída" (NORA, 1993, p. 12). É evidente o quanto o discurso positivista conduziu à legitimação dos lugares de memória por muito tempo. A escolha da Casa do Morro como símbolo do município foi pautada em uma história positiva, que atribuiu maior destaque e importância à família Azambuja. Consequentemente, o discurso que se sucedeu a partir de então, continuou exaltando a família e associando a história de Cruzeiro do Sul somente à atuação dos Azambuja. Foi o discurso historiográfico que depositou na Casa do Morro a incumbência de resguardar essa história e, consequentemente, a conduziu para que se tornasse um lugar de memória para a população. "E se, em compensação, a história não se apoderasse deles para deformá-los, transformá-los, sová-los e petrificá-los eles não se tornariam lugares de memória" (NORA, 1993, p. 13).

A importância delegada à Casa do Morro a consolidou como um grande testemunho capaz de armazenar todas as informações possíveis sobre o passado, um lugar de memória. Sentimos a obrigação individual de internalizar essa memória, que não é mais uma prática social, pois todos os grupos humanos sentem a necessidade de ir em busca de sua própria constituição, de encontrar suas origens. No entanto, "a passagem da memória para a história obrigou cada grupo a redefinir sua identidade pela revitalização de sua própria história" (NORA, 1993, p. 17). Os lugares de memória atuam como reforço de identidade, e quando há a preocupação com o seu desaparecimento, há também a preocupação com o significado do presente e a incerteza do futuro.

Para um lugar se tornar um lugar de memória deve haver o sentimento de "vontade de memória", logo percebemos este sentimento ativo para com a Casa do Morro, proveniente não somente dos Amigos da Ca- 
sa do Morro, mas também de grande parcela da população que se identifica com o monumento. A Casa do Morro abriga três aspectos da memória: a memória arquivo, memória dever e memória distância (NORA, 1993). A primeira se refere ao acúmulo de informações guardadas; a segunda, à obrigação que sentimos em buscar todas essas informações, pois nos obrigamos a relembrar e reencontrar o pertencimento nesses lugares, princípio da identidade; já a memória distância está vinculada ao fato de que a Casa do Morro reúne uma história que ocorreu no passado, e que não está mais acessível a nós. A isso se deve a grande vontade e necessidade de preservá-la, para que este lugar de memória bloqueie o trabalho do esquecimento e do tempo.

Ainda não está definida qual a finalidade da Casa do Morro após a restauração, mas o grupo Amigos da Casa do Morro já possui várias propostas. Como meios para buscar a preservação do patrimônio, para além da sua materialidade, apontam atividades educativas provenientes da Secretaria de Educação diretamente nas escolas para que a história do município e da Casa do Morro seja repassada aos alunos, assim como a importância da preservação do patrimônio histórico. A ideia é organizar na Casa um espaço em que sejam desenvolvidas diversas atividades culturais, como artesanato, música, dança e teatro, com uma parceria entre o Poder Público e a comunidade que promova o turismo e, consequentemente, o comércio local. Também foi sugerida a organização de uma biblioteca, museu e Centro Histórico Municipal. Esse último teria a função de realizar pesquisas constantes a respeito da história de Cruzeiro do Sul e da Casa do Morro que fossem divulgadas à população. Em suma, indiferente do projeto que for proposto, deverá promover o afeto e a sensação de pertencimento dos cruzeirenses para com a Casa do Morro.

Não restam dúvidas sobre o símbolo de identidade e memória que a Casa do Morro representa para a população, e o quanto ela espera a sua restauração e deseja que o monumento se torne um espaço cultural para toda comunidade com uma função social, e não apenas contemplativa. Basta aguardar para ver o que acontecerá com a Casa e de que maneira o grupo Amigos da Casa do Morro irá articular-se para ter seu objetivo concluído. A Casa do Morro se constitui em um lugar de memória que provoca na população o desejo de patrimonialização, uma reivindicação autêntica da valorização do patrimônio e inserção deste em uma narrativa coletiva.

\section{Considerações finais}

A partir do estudo realizado, foi possível constatar que o processo de patrimonialização da Casa do Morro ocorreu de acordo com a valorização do patrimônio material de Cruzeiro do Sul, influenciada pelo destaque dado à atuação da família Azambuja, considerada pioneira na história do município. A Casa do Morro foi escolhida como símbolo da cidade pelos representantes municipais justamente por estes entenderem que a identidade do município deveria estar pautada na história da família fundadora do núcleo urbano de Cruzeiro do Sul. Essa escolha influenciou no modo como a história do município foi contada ao longo do tempo, influenciada por uma história positivista, aquela que dá destaque apenas para os fatos e personagens politicamente mais destacados. Seguiu-se uma concepção arcaica de patrimônio, que considera como patrimônio apenas os monumentos históricos e artísticos herdados de gerações anteriores, vinculados aos grupos sociais de elite.

Por meio de pesquisa documental e bibliográfica, conseguimos entender quem eram os Azambujas e porque a Casa do Morro sempre foi tão glorificada. Uma família da elite, que se utilizou da política dos casamentos, da carreira militar e da comercialização de 
terras para manter seu status social. Uma elite possuidora de escravos que fez uso de grilagens e documentos falsos para adquirir áreas de terra e que mesmo assim, deteve toda pompa no discurso histórico. A pesquisa documental não foi esgotada, e ainda há uma série de fontes nos arquivos que precisam ser analisados.

A história de Cruzeiro do Sul sempre foi remetida e reduzida à atuação dos Azambuja, em detrimento dos africanos escravizados, dos povos indígenas e daqueles denominados lavradores nacionais. O modo como a patrimonialização da Casa do Morro foi conduzida contribuiu para a legitimação desse discurso, porém, isso não significou a preservação das características estruturais originais da obra. Talvez por falta de conhecimento ou de verba, a Casa do Morro sofreu inúmeras intervenções que prejudicaram a sua originalidade e que provocaram, em alguns casos, uma descaracterização. Somente após dez anos do tombamento é que o prédio passou a receber interferências que buscam sua reestruturação e o mais interessante é que essa iniciativa partiu da própria sociedade, com a criação do grupo Amigos da Casa do Morro.

O grupo se sente identificado com a Casa, pois acredita que ela representa a história de Cruzeiro do Sul. Por meio do estudo de conceitos como memória e identidade, percebemos que a Casa do Morro é um lugar de memória, que abriga uma memória a que não temos mais acesso e que nos identifica, por isso a vontade de preservá-la. Os Amigos da Casa do Morro buscam a restauração do prédio e o funcionamento de um espaço que promova várias atividades culturais. Ainda não é sabido o destino que terá a Casa do Morro, mas sabemos que ela clama por uma restauração e por um projeto de Educação Patrimonial que a transforme em um recurso educativo e, principalmente, para a divulgação de uma história que prima pelo respeito à diversidade.

\section{Referências}

ARÉVALO, Marcia Conceição da Massena. Lugares de memória ou a prática de preservar o invisível através do concreto. In: I Encontro Memorial do Instituto de Ciências Humanas e Sociais, Mariana, 2004. Anais... Ouro Preto: UFOP.

$\operatorname{ATA~}^{\circ}$ 020/2014, $1^{\circ}$ de outubro de 2014. Câmara Municipal de Vereadores de Cruzeiro do Sul.

BERLATTO, Odir. A construção da identidade social. Revista do Curso de Direito da FSG, Caxias do Sul, n. 5, 2009.

BRASIL. Decreto-lei n. 3.365, de 21 de junho de 1941. Dispõe sobre desapropriações por utilidade pública. Disponível em: <http://www.planalto.gov.br/ccivil_03/decreto-lei/Del3365.htm>. Acesso em: 26 out. 2016.

CADERNO CULTURAL: A “Casa Branca”. Centro Cultural 25 de Julho "Vale do Taquari”, Estrela, n. 03, agosto de 1985.

CANDAU, Joël. Bases antropológicas e expressões mundanas da busca patrimonial: memória, tradição e identidade. Revista Memória em Rede, Pelotas, v. 1, n. 1, 2010.

. Memória e identidade. São Paulo: Contexto, 2014.

CARVALHO, Aline Vieira de; FUNARI, Pedro Paulo. Memória e Patrimônio: diversidade e identidades. Revista Memória em Rede, v.02, 2010, p.7-16.

CHRISTILLINO, Cristiano Luís. Estranhos em seu próprio chão: o processo de apropriações e expropriações de terras na Província de São Pedro do Rio Grande do Sul (o Vale do Taquari no período de 1840-1889). São Leopoldo, Dissertação (Mestrado), Universidade do Vale do Rio dos Sinos, 2004. 
A CASA DO MORRO: UM LUGAR DE MEMÓRIA EM CRUZEIRO DO SUL/RS

. Litígios ao sul do Império: a Lei de Terras e a consolidação política da Coroa no Rio Grande do Sul (18501880). Niterói, Tese (Doutorado), Universidade Federal Fluminense, 2010.

COSTA, Debora Regina Magalhães da. Aspectos críticos em obras de restauração arquitetônica no estado: a experiência do arquiteto Edegar Bittencourt da Luz. Porto Alegre. Trabalho de Conclusão (Mestrado), Universidade Federal do Rio Grande do Sul, 2005.

CRUZEIRO DO SUL (Município). Projeto de Lei no 052-03, de 15 de junho de 2015. Cruzeiro do Sul, RS, 15 jun. 2015, fotocópia. $1 \mathrm{p}$.

DUARTE, Luiz Fernando Dias. Memória e reflexividade na cultura ocidental. In: ABREU, Regina; CHAGAS, Mário. (Org.). Memória e patrimônio: ensaios contemporâneos. Rio de Janeiro: Lamparina, 2009.

FONSECA, Maria Cecília Londres. O Patrimônio em processo: trajetória da política federal de preservação no Brasil. $2^{\text {a }}$ ed. Rio de Janeiro: Editora UFRJ, 2005.

. Para além da pedra e cal: por uma concepção ampla de patrimônio cultural. In: ABREU, Regina; CHAGAS, Mário (orgs.). Memória e patrimônio: ensaios contemporâneos. Rio de Janeiro: Lamparina, 2009.

FUNARI, Pedro Paulo; PELEGRINI, Cássia Araújo. Patrimônio histórico e cultural. Rio de Janeiro: Jorge Zahar Ed., 2006.

HARNISCH, Wolfgang Hoffmann. O Rio Grande do Sul. Porto Alegre: Livraria do Globo, 1941.

HISTÓRIAS que os cupins podem apagar. Zero Hora, Porto Alegre, p. 26, 3 jan. 1999.

HORTA, Maria de Lourdes Parreiras; GRUNBERG, Evelina; MONTEIRO, Adriane Queiroz. Guia Básico de Educação Patrimonial, Brasília: Instituto do Patrimônio Histórico e Artístico Nacional, Museu Imperial, 1999.

INVENTÁRIO post-mortem do Cartório de Orphãos e Ausentes de Lageado, no 371, de 1902. APERS.

KNAUSS, Paulo. Usos do passado e patrimônio cultural. In: REINHEIMER, Dalva; NEUMANN, Rosane Marcia (Orgs.). Patrimônio histórico nas comunidades teuto-brasileiras: história, memória e preservação. São Leopoldo: Oikos, 2014.

LAJEADO (Município). Decreto nº 811, de 7 de agosto de 1962. Lajeado, RS, 7 ago. 1962, fotocópia. 1 p.

LOCATELLI, Cesar Ricardo; SAIBRO, Fabricio de; SCHNEIDER, Leani Maria (Org.). Cruzeiro do Sul em fotos. Lajeado: Ed. da Univates, 2012.

NICOLINI, Cristiano. A construção da identidade territorial a partir das manifestações culturais no Vale do Taquari: etnografia dos grupos de danças folclóricas alemãs de Estrela e do $47^{\circ}$ Festival do Chucrute. Santa Cruz do Sul, Dissertação (Mestrado), Universidade de Santa Cruz do Sul, 2013.

NORA, Pierre. Entre memória e história: a problemática dos lugares. Proj. História. São Paulo, 1993.

PELEGRINI, Sandra, A. C. Cultura e natureza: os desafios das práticas preservacionistas na esfera do patrimônio cultural e ambiental. Rev. Bras. Hist., São Paulo, v. 26, n. 51, jan./jun. 2006.

PELEGRINI, Sandra C. Patrimônio cultural: consciência e preservação. São Paulo: Brasiliense, 2009.

POULOT, Dominique. Uma história do patrimônio no Ocidente. São Paulo: Estação Liberdade, 2009.

SCHIERHOLT, José Alfredo. Cruzeiro do Sul e sua história. Porto Alegre: Evangraf, 2010.

Submissão: 29/04/2017

Aceite: 06/08/2017 